\title{
Impact of Prenatal Antimicrobial Treatment on Fetal Brain Damage Due to Autogenous Fecal Peritonitis in Wistar Rats: a Histomorphometric Study*
}

Neylane Nyéria Coelho Batista Gadelha1, Diego Nery Benevides Gadelha², Alexandre Rolim da Paz ${ }^{3}$, Maria Cecília Santos Cavalcanti Melo ${ }^{4}$, Thárcia Kiara Beserra Oliveira ${ }^{5}$, Carlos Teixeira Brandt 6

\section{Abstract}

Purpose: To investigate brain neuronal density in newborn rats whose mothers were subjected to fecal peritonitis and compare findings between rats born to mothers treated and not treated with antimicrobials.

Methods: Peritonitis was induced with a 10\% fecal suspension (4 $\mathrm{mL} / \mathrm{kg}$ ) in 2 pregnant rats. Of these, 1 received antimicrobial treatment 24 hours after peritonitis induction: moxifloxacin and dexamethasone plus $2 \mathrm{~mL}$ of the inner bark of the Schinus terebinthifolius raddi extract. One pregnant rat underwent no intervention and served as a control.

Results: The newborn brains of rats born to mothers with fecal peritonitis were significantly smaller and of less firm consistency. Brain neuronal density was lower in the untreated group than in the control and treated groups $(P<0.01)$.

Conclusions: Untreated peritonitis caused brain damage in the offspring, which was averted by effective early antimicrobial treatment. This approach may provide an early avenue for translation of such therapy in humans.

Keywords

Peritonitis; Brain Injuries; Rats.
1 Fellow MSc degree, Postgraduate Program in Surgery, Health Sciences Center, Universidade Federal de Pernambuco (UFPE), Recife, PE, Brazil.

$2 \mathrm{PhD}$, Postgraduate Program in Surgery, Health Sciences Center, UFPE, Recife, PE, Brazil.

3 Assistant Professor, Pathology, Universidade Federal da Paraíba (UFPB), João Pessoa, PB, Brazil.

4 Fellow PhD degree, Postgraduate Program in Surgery, Health Sciences Center, UFPE, Recife, PE, Brazil.

5 Fellow PhD degree, Postgraduate Program in Agricultural Engineering, Universidade Federal de Campina Grande (UFCG), PB, Brazil.

6 PhD, Head, Scientific Methodology and Pediatric Surgery, UFPE, Recife, PE, Brazil.

*: Research performed at Laboratory of Experimental Surgery, Department of Surgery, Faculdade de Ciências Médicas de Campina Grande, Campina Grande, PB, Brazil. Part of Master degree thesis, Postgraduate Program in Surgery, Universidade Federal de Pernambuco. Advisor: Carlos Teixeira Brandt.

\section{Contact information:}

Neylane Nyéria Coelho Batista Gadelha.

Address: Av. Senador Argemiro de Figueiredo, 1901. 58411-020. Campina Grande, PB. Brazil.

Tel: +55-83-98105-8023. 


\section{Introduction}

Sepsis and septic shock are serious clinical problems and remain a major cause of morbidity and mortality in intensive care unit patients. No specific antiseptic treatment is currently available and patient care relies heavily on early recognition, allowing timely interventions-such as antibiotic administration, source control measures if necessary, and resuscitation with intravenous fluids and vasoactive agents [Cohen, Vincent, Adhikari, Machado, Angus, Calandra, Jaton, Giulieri, Delaloye, Opal, Tracey, van der Poll, \& Pelfrene, 2015].

Prenatal infection is a stressful experience leading to enhanced susceptibility to mental illness in humans. Pregnancy itself is a unique condition of immune tolerance that cannot be attributed merely to generalized immunosuppression. A number of mechanisms have been proposed, including nonself recognition, immunomodulation of specific inflammatory cell populations, and a Th2-directed immune response, which are mediated by both localized and systemic reactions. Moreover, an inflammatory response toward the conceptus is no longer regarded as an obligatory deleterious response. Instead, it is considered an important factor required for normal growth and development [Adar, Grisaru-Granovsky, Ben Ya'acov, Goldin, \& Bar-Gil Shitrit, 2015].

There is evidence that intrauterine inflammation, such as chorioamnionitis, in animal models can affect microglia, astrocytes, axonal growth, and apoptosis [Gavilanes, Strackx, Kramer, Gantert, Van den Hove, Steinbusch, Garnier, Cornips, Steinbusch, Zimmermann, \& Vles, 2009; Kallapur, Presicce, Rueda, Jobe, \& Chougnet, 2014; Lante, Meunier, Guiramand, De Jesus Ferreira, Cambonie, Aimar, Cohen-Solal, Maurice, Vignes, \& Barbanel, 2008]. In rats, oxidative stress and shortage of glutathione occurred in the fetal brain after maternal lipopolysaccharide administration, and these responses may result in neurodevelopmental deficits in the offspring [Burd, Balakrishnan, \& Kannan, 2012].
Studies in animal models of maternal inflammation during pregnancy play a key role in elucidating the mechanisms involved in fetal brain injury associated with exposure to the maternal milieu. Such models have resulted in fetal microglial activation, neurotoxicity, and motor and behavioral deficits in the offspring [Burd et al., 2012].

We have previously demonstrated morphological brain damage in newborn rats whose mothers were subjected to autogenous fecal peritonitis in early pregnancy, and this damage was ameliorated with effective antimicrobial therapy [Brandt, Melo, GadeIha, Gadelha, Oliveira, \& Falcao, 2014]. However, the histologic findings of this brain damage have not been investigated. The present study was therefore designed to evaluate brain damage in newborn rats whose mothers were subjected to autogenous fecal peritonitis in early pregnancy by means of histologic and histomorphometric analysis of brain neuronal density and compare findings between rats born to mothers treated and not treated with antimicrobials and with normal brain tissue.

\section{Methods}

This prospective study was approved by the Ethics Committee of the Medical School of Campina Grande, Paraiba, Brazil. Animal handling and experimentation followed international standards and guidelines for the care and use of laboratory animals.

The study was conducted in two phases. First, we developed a model of autogenous fecal peritonitis in pregnant Wistar rats aiming to produce significant brain damage in the offspring. On day 9 of pregnancy, $4 \mathrm{~mL} / \mathrm{kg}$ of autogenously filtered $10 \%$ fecal suspension were injected into the abdominal cavity of 2 rats. One pregnant rat underwent no intervention and served as a control. Both infected and uninfected (control) rats were housed in polypropylene cages and maintained in a ventilated and temperature-controlled chamber $\left(24 \pm 1^{\circ} \mathrm{C}\right)$ on 
a standard 12:12 light-dark cycle (lights on at 07:00 AM), with free access to food and tap water. All rats were checked daily until the birth of the offspring.

Second, 1 infected pregnant rat was randomly selected and treated with a single intravenous injection of moxifloxacin $(40 \mathrm{mg} / \mathrm{kg}$ ) and dexamethasone $(0.2 \mathrm{mg} / \mathrm{kg})$. Both drugs were injected 24 hours after peritonitis induction. Additionally, $2 \mathrm{~mL}$ of the inner bark of the Schinus terebinthifolius raddi extract were injected into the abdominal cavity, according to a previous protocol [Melo, Gadelha, Oliveira, \& Brandt, 2014].

Immediately after birth, 8 newborns from each rat (treated, untreated, and control) were separated from their mothers, inspected for any congenital malformation, and weighed on a precision scale. Then, they were euthanized by halothane inhalation and decapitated.

After delivery, the female rats were assessed for findings associated with peritonitis by abdominal and thoracic examination. The morphological characteristics of the newborns were also described, with special attention to the head structures and central nervous system.

\section{Histopathology}

The newborn rat brains were carefully removed, weighed on a precision scale, and immediately fixed in $10 \%$ buffered formalin for 3 days. The fixed brains were then embedded in paraffin and sectioned after dehydration and vitrification. Sections were deparaffinized with xylene and ethanol and stained with hematoxylin for 10 minutes. Then, sections were washed with water and differentiated with hydrochloric acid and ethanol prior to staining with eosin for 2 minutes. Slides containing sections of the brain cortex, hippocampus and lateral ventricle were arranged in trays and examined under a light microscope at 400x magnification. For each part of the brain, 5 areas were randomly selected for analysis. The best section was used for the final assessment.

\section{Histomorphometric analysis}

Microscope images (400x magnification) were digitized. To calculate the number of cell nuclei, the area occupied by cells and total area of the studied image (neuronal density) were measured using ImageJ [Girish \& Vijayalakshmi, 2004; Schneider, Rasband, \& Eliceiri, 2012]. All histomorphometric analyses were performed by a single examiner.

\section{Statistical analysis}

Quantitative data were expressed as means (standard deviations) and presented in a box plot. Because the data were non-normally distributed, the Mann-Whitney test was used for unpaired comparisons between mean differences and the KruskalWallis test followed by Dunn's post hoc test was used for multiple comparisons among means. Statistical analyses were performed using GraphPad Prism, version 6.0. Values of $P \leq 0.05$ were considered statistically significant.

\section{Results}

Brain weight was significantly increased in the untreated group compared with control and treated groups ( $P=0.0002$ ) (Tables 1, 2 \& Figure 1).

Regarding cell count, the number of cells was significantly decreased in the untreated group ( $P=$ 0.0004 ) (Table 3, 4 \& Figure 2).

Measurement of brain cells $\left(2 \times 10^{3}\right.$ pixels) showed a significant increase in cell size in the untreated group ( $P=0.0005)$ (Table 5, 6 \& Figure 3).

There was no difference in total brain area between the 3 groups $(P=0.4428$ ) (Table 7 \& Figure 4).

Table 1. Brain weight (in grams) in the three groups.

\begin{tabular}{|l|c|c|c|}
\hline & Treated & Untreated & Control \\
\hline $\mathrm{n}$ & 8 & 8 & 8 \\
\hline Minimum & 0.1650 & 0.2300 & 0.1210 \\
\hline Median & 0.1915 & 0.2470 & 0.1730 \\
\hline Maximum & 0.2470 & 0.2740 & 0.1900 \\
\hline Mean & 0.1986 & 0.2479 & 0.1680 \\
\hline Standard deviation & 0.02667 & 0.01376 & 0.02102 \\
\hline
\end{tabular}


Table 2. Analytical assessment of brain weight (in grams).

\begin{tabular}{|l|c|c|c|c|}
\hline Dunn's multiple comparison test & Mean rank diff. & Significant? & Summary & Adjusted P-value \\
\hline Untreated vs. Treated & 8.063 & No & non-significant & 0.0677 \\
\hline Control vs. Treated & -6.375 & No & non-significant & 0.2139 \\
\hline Control vs. Untreated & -14.44 & Yes & - & 0.0001 \\
\hline
\end{tabular}

Table 3. Brain cell counts in the three groups.

\begin{tabular}{|l|c|c|c|}
\hline & Treated & Untreated & Control \\
\hline $\mathrm{n}$ & 8 & 8 & 8 \\
\hline Minimum & 1148.0 & 765.0 & 1094.0 \\
\hline 25th percentile & 1210 & 859.3 & 1299 \\
\hline Median & 1299 & 901.5 & 1599 \\
\hline 75th percentile & 1541 & 1077 & 1753 \\
\hline Maximum & 1757 & 1101 & 1856 \\
\hline Mean & 1374 & 942.6 & 1532 \\
\hline Standard deviation & 205.9 & 121.7 & 271.9 \\
\hline Standard error of the mean & 72.81 & 43.02 & 96.14 \\
\hline
\end{tabular}

Figure 1: Distribution of brain weight.

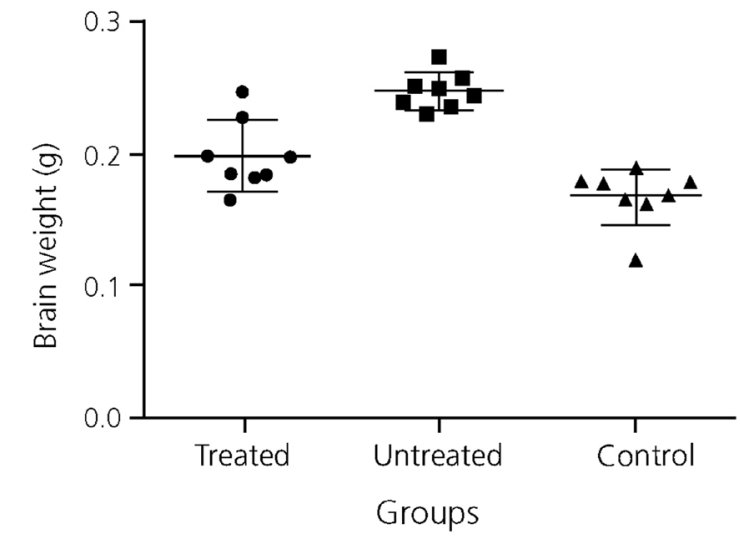

Table 4. Analytical assessment of brain cell counts.

\begin{tabular}{|l|c|c|c|c|}
\hline Dunn's multiple comparison test & Mean rank diff. & Significant? & Summary & Adjusted P-value \\
\hline Untreated vs. Control & -10.50 & Yes & - & 0.0089 \\
\hline Treated vs. Control & 2.625 & No & non-significant & $>0.9999$ \\
\hline Treated vs. Untreated & 13.13 & Yes & - & 0.0006 \\
\hline
\end{tabular}

Table 5. Brain cell size $\left(2 \times 10^{3}\right.$ pixels $)$ in the three groups.

\begin{tabular}{|l|c|c|c|}
\hline & Treated & Untreated & Control \\
\hline $\mathrm{n}$ & 8 & 8 & 8 \\
\hline Minimum & 276.0 & 398.0 & 274.0 \\
\hline 25th percentile & 291.0 & 409.8 & 295.8 \\
\hline Median & 306.5 & 471.5 & 313.0 \\
\hline 75th percentile & 347.8 & 547.3 & 331.0 \\
\hline Maximum & 365.0 & 561.0 & 334.0 \\
\hline Mean & 314.9 & 477.0 & 311.1 \\
\hline Standard deviation & 32.19 & 63.98 & 21.00 \\
\hline Standard error of the mean & 11.38 & 22.62 & 7.424 \\
\hline
\end{tabular}

Figure 2: Distribution of cell counts.

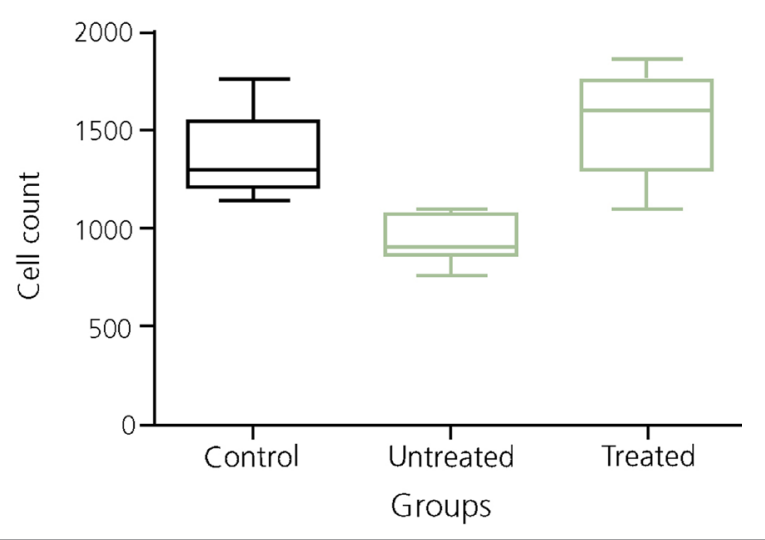

Table 6. Analytical assessment of cell size ( $2 \times 10^{3}$ pixels).

\begin{tabular}{|l|c|c|c|c|}
\hline Dunn's multiple comparison test & Mean rank diff. & Significant? & Summary & Adjusted P-value \\
\hline Untreated vs. Control & 12.13 & Yes & - & 0.0018 \\
\hline Treated vs. Control & 0.2500 & No & non-significant & $>0.9999$ \\
\hline Treated vs. Untreated & -11.88 & Yes & - & 0.0023 \\
\hline
\end{tabular}


Figure 3: Distribution of cell size.

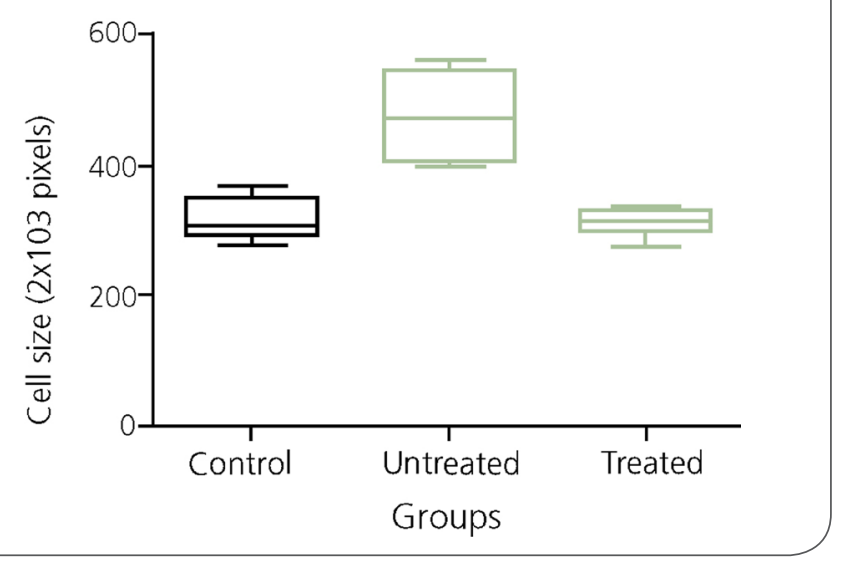

Figure 4: Distribution of total brain area.

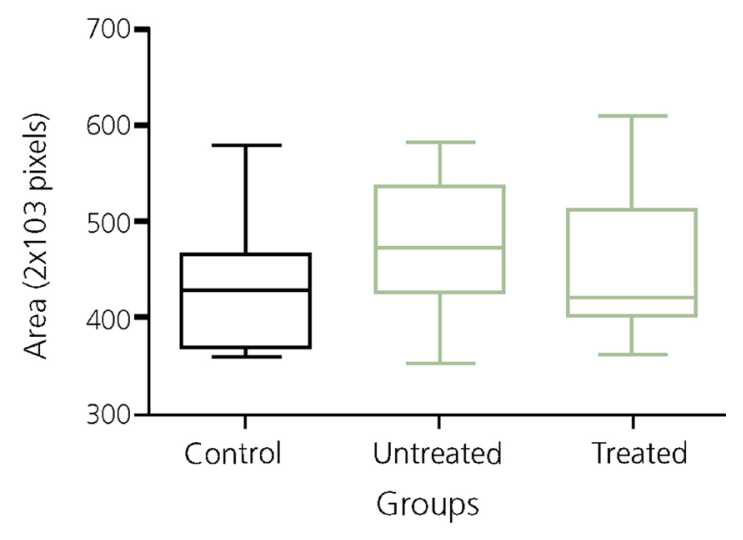

Table 7. Analytical assessment of total brain area ( $2 \times 10^{3}$ pixels).

\begin{tabular}{|l|c|c|c|c|}
\hline \multicolumn{1}{|c|}{ Dunn's multiple comparison test } & Mean rank diff. & Significant? & Summary & Adjusted P-value \\
\hline Untreated vs. Control & 4.250 & No & non-significant & 0.6877 \\
\hline Treated vs. Control & 0.8125 & No & non-significant & $>0.9999$ \\
\hline Treated vs. Untreated & -3.438 & No & non-significant & 0.9924 \\
\hline
\end{tabular}

\section{Discussion}

Although infection is a well-known complication of pregnancy, pregnancy-associated severe sepsis (PASS) has not been as well characterized, and only limited population-based data are available. In pregnancies complicated by acute appendicitis, this condition often promotes severe infection, including PASS, and the newborns are at increased risk of adverse outcomes. Thus, delayed or conservative management should be avoided due to the high risk of adverse pregnancy outcomes, and measures should be taken to decrease the risk of peritonitis and its associated morbidities [Abbasi, Patenaude, \& Abenhaim, 2014].

In the present study, we further investigated the effect of severe infection due to autogenous fecal peritonitis on the brain of offspring of Wistar rats [Brandt et al., 2014] by comparing rats born to a mother that received no antimicrobial treatment during pregnancy with rats born to a mother that received a very aggressive treatment. The first observation was the histologic confirmation of the macroscopic findings in the brain, particularly the jelly-like appearance of the organ (periventricular leukomalacia) [Brandt et al., 2014]. Additionally, the mean brain weight of untreated newborns was significantly increased compared with treated and control rats, and the most likely explanation is that the untreated newborns developed severe neuroinflammation in the brain, increasing interstitial fluid infiltration. In this regard, a fluid-like substance pouring from these brains was observed, and the brains were edematous. Consistent with this hypothesis, the mean neuronal density of these brains was significantly decreased compared with treated and control rats.

Reduced neuronal density can also be the end result of neurotoxicity in the central nervous system due to endotoxemia caused by autogenously induced peritonitis and bacterial translocation from the abdominal cavity to the bloodstream [Burd et al., 2012]. Apoptosis may also be involved in this process of brain injury associated with neuronal death [Gavilanes et al., 2009; Kallapur et al., 2014; Lante et al., 2008; Nitsos, Rees, Duncan, Kramer, Harding, Newnham, \& Moss, 2006]. In addition to 
periventricular leukomalacia, in humans this injury has also been associated with cerebral palsy and a spectrum of neurodevelopmental disorders, such as autism and schizophrenia [Patterson, 2009]. However, it remains a matter of debate whether these early histological changes due to a toxemic insult from the mothers could be averted by timely, aggressive antimicrobial therapy. The almost normal brain neuronal density lends support to this hypothesis.

An interesting point of discussion, taking into account the extraordinary adaptive mechanism of rats, is whether these animals will recover normal brain function after severe infectious toxicity transmitted from their mothers, due to newborn neuronal plasticity and neurogenesis. Further functional research is warranted to determine the likelihood of this outcome.

\section{Conclusions}

Untreated peritonitis during pregnancy caused brain damage in the offspring of Wistar rats, but effective early antimicrobial treatment prevented the decrease in brain neuronal density. In humans, intraabdominal infection in pregnant women may be associated with brain damage of their conceptuses, and this may be averted by using appropriate early therapeutic intervention. Because translational evidence is not yet available for the mechanisms investigated in this study, this approach may provide an early avenue for translation of such therapy in humans.

\section{Financial disclosure}

The authors have no financial relationships relevant to this article to disclose.

\section{Conflict of Interest}

The authors have no conflicts of interest to disclose.

\section{References}

- Abbasi, N., Patenaude, V., \& Abenhaim, H. A. (2014). Evaluation of obstetrical and fetal outcomes in pregnancies complicated by acute appendicitis. Archives of Gynecology and Obstetrics, 290(4), 661-667. doi: 10.1007/s00404-014-3276-7

- Adar, T., Grisaru-Granovsky, S., Ben Ya'acov, A., Goldin E., \& BarGil Shitrit A. (2015). Pregnancy and the immune system: general overview and the gastroenterological perspective. Digestive Diseases and Sciences, 60(9), 2581-2589. doi: 10.1007/s10620015-3683-z

- Brandt, C. T., Melo, M. C., Gadelha, D. N., Gadelha, N. N., Oliveira, T. K., \& Falcao, M. P. (2014). Brain damage and congenital cataract due to autogenously fecal peritonitis in pregnant Wistar rats. Acta Cirúrgica Brasileira, 29(10), 681-687. Retrieved from http://www.ncbi.nlm.nih.gov/pubmed/25318001

- Burd, I., Balakrishnan, B., \& Kannan, S. (2012). Models of fetal brain injury, intrauterine inflammation, and preterm birth. American Journal of Reproductive Immunology, 67(4), 287-294. doi: 10.1111/j.1600-0897.2012.01110.x

- Cohen, J., Vincent, J. L., Adhikari, N. K., Machado, F. R., Angus, D. C., Calandra, T., Jaton, K., Giulieri, S., Delaloye, J., Opal, S., Tracey, K., van der Poll, T., \& Pelfrene, E. (2015). Sepsis: a roadmap for future research. The Lancet. Infectious Diseases, 15(5), 581-614. doi: 10.1016/S1473-3099(15)70112-X

- Gavilanes, A. W., Strackx, E., Kramer, B. W., Gantert, M., Van den Hove, D., Steinbusch, H., Garnier, Y., Cornips, E., Steinbusch, H., Zimmermann, L., \& Vles, J. (2009). Chorioamnionitis induced by intraamniotic lipopolysaccharide resulted in an intervaldependent increase in central nervous system injury in the fetal sheep. American Journal of Obstetrics and Gynecology, 200(4), 431-438. doi: 10.1016/j.ajog.2008.12.003

- Girish, V. \& Vijayalakshmi, A. (2004). Affordable image analysis using $\mathrm{NIH}$ Image/ImageJ. Indian Journal of Cancer, 41(1), 47. Retrieved from http://www.ncbi.nlm.nih.gov/ pubmed/15105580

- Kallapur, S. G., Presicce, P., Rueda, C. M., Jobe, A. H., \& Chougnet, C. A. (2014). Fetal immune response to chorioamnionitis. Seminars in Reproductive Medicine, 32(1), 56-67. doi: 10.1055/ s-0033-1361823

- Lante, F., Meunier, J., Guiramand, J., De Jesus Ferreira, M. C., Cambonie, G., Aimar, R., Cohen-Solal, C., Maurice, T., Vignes, M., \& Barbanel, G. (2008). Late N-acetylcysteine treatment prevents the deficits induced in the offspring of dams exposed to an immune stress during gestation. Hippocampus, 18(6), 602-609. doi: 10.1002/hipo.20421 
- Melo, M. C., Gadelha, D. N., Oliveira, T. K., \& Brandt, C. T. (2014). Alcohol extract of Schinus terebinthifolius raddi (anacardiaceae) as a local antimicrobial agent in severe autogenously fecal peritonitis in rats. Acta Cirúrgica Brasileira, 29 Suppl 1:52-56. Retrieved from http://www.ncbi.nlm.nih.gov/ pubmed/25185057

- Nitsos, I., Rees, S. M., Duncan, J., Kramer, B. W., Harding, R., Newnham, J. P., \& Moss, T. J. (2006). Chronic exposure to intraamniotic lipopolysaccharide affects the ovine fetal brain. Journal of the Society of Gynecology Investigation, 13(4), 239-247. doi: 10.1016/j.jsgi.2006.02.011

- Patterson, P. H. (2009). Immune involvement in schizophrenia and autism: etiology, pathology and animal models. Behavioural Brain Research, 204(2), 313-21. doi: 10.1016/j.bbr.2008.12.016

- Schneider C. A., Rasband W. S. \& Eliceiri K. W. (2012). NIH Image to ImageJ: 25 years of image analysis. Nat Methods, 9(7), 671-675. Retrieved from http://www.ncbi.nlm.nih.gov/ pubmed/22930834

Publish in International Archives of Medicine

International Archives of Medicine is an open access journal publishing articles encompassing all aspects of medical science and clinical practice. IAM is considered a megajournal with independent sections on all areas of medicine. IAM is a really international journal with authors and board members from all around the world. The journal is widely indexed and classified Q2 in category Medicine. 